\title{
Cambios y continuidades en las representaciones actuales sobre Tacuara ${ }^{1}$
}

\author{
María Valeria Galván ${ }^{2}$
}

Resumen: El objetivo principal de este artículo es identificar en narrativas actuales los cambios en los regímenes de memoria acerca de uno de los más importantes predecesores de las guerrillas de los setenta en la Argentina, la agrupación nacionalista Tacuara. Este controversial grupo de extrema derecha, nacido al calor de las luchas políticas urbanas posteriores a la caída de Perón a fines de los cincuenta, proveyó de militantes a la guerrilla izquierdista luego de su disolución. Treinta años después de que esta agrupación se disolviese, volvieron a aflorar las controversias en torno a su violencia política, su antisemitismo y el destino en el otro extremo del espectro ideológico de muchos de sus integrantes.

La reconfiguración producida en los regímenes de memoria sobre la historia reciente argentina en los últimos años condujo hacia una revalorización de la militancia setentista y Tacuara (debido a su carácter de antecesor de éstas) también se benefició de estas transformaciones. Por esto, el presente artículo analiza las narrativas actuales de producciones audiovisuales, medios gráficos y discursos de los ex militantes tacuaristas, entre los años 1996-2008, donde se pueden rastrear las transformaciones principales en las discursos sociales respecto de este grupo.

Palabras clave: Tacuara, discursos sociales, regímenes de memoria.

\footnotetext{
${ }^{1}$ Este artículo forma parte de la tesis El Movimiento Nacionalista Tacuara y sus agrupaciones derivadas: una aproximación desde la historia cultural, financiada con beca Tipo I del CONICET.

${ }_{2}^{2}$ Magíster en Sociología de la Cultura, Instituto de Desarrollo Humano, Universidad Nacional General Sarmiento. Dirección postal: Moreno 1287 2N, Ciudad de Buenos Aires, Argentina, CP: 1091. Correo electrónico: galvan.valeria@googlemail.com
}

Revista Eletrônica da ANPHLAC, n.11, p. 8-39, jul./dez. 2011.

http://revista.anphlac.org.br/index.php/revista 
Abstract: The main objective of this article is to identify in contemporary narratives the changes in the memory regimes on one of the most important predecessors of the guerrillas of the 70s in Argentina, namely the nationalist group, Tacuara, an extreme right-wing group born at the heat of the political street battles after the fall of Perón by the end of the 50s. Tacuara was later not only a predecessor but also a known provider of members and warfare knowledge for the guerrillas. Thirty years after this group was dissolved, the controversy aroused by its political violence, its anti-Semitism and the destiny in the Left of many of its former members comes back.

The change in the memory regimes about Argentina's recent history led to a re-appreciation of the leftist militancy of the seventies. Public's memory of Tacuara profited from this as well. For these reasons, this article analyzes the contemporary narratives of audiovisual productions, the press and of members of these organizations, during the period between 1996-2008, where the changes in the contemporary social discourses on Tacuara can be traced.

Key words: Tacuara, social discourses, memory regimes.

\section{Introducción}

Tacuara fue una de las primeras organizaciones juveniles - nacionalista, antisemita y que se valió de la violencia política - surgidas en la Argentina luego de la caída del presidente Juan Domingo Perón en 1955, momento en el cual se inició en el pais el proceso de radicalización política que culminaría con la última dictadura militar (1976-1983).

Más de treinta años después, la historia de Tacuara - que parecía haber quedado en el olvido popular - emergió como pasado oscuro y vergonzante de funcionarios y empresarios del gobierno del presidente Carlos Saúl Menem, durante la década de los noventa. Sin embargo, a comienzos del nuevo milenio, en el marco de una resignificación

Revista Eletrônica da ANPHLAC, n.11, p. 8-39, jul./dez. 2011.

http://revista.anphlac.org.br/index.php/revista 
de la militancia de los setenta a partir de las nuevas políticas de memoria impulsadas por la presidencia de Néstor Kirchner, las producciones discursivas sobre Tacuara vuelven a girar sobre sí. De este modo, nace para la opinión pública una nueva Tacuara. En general, por intermedio de relatos biográficos de ex-militantes que posteriormente formarían parte de organizaciones guerrilleras de izquierda en los setenta, Tacuara aparece como una suerte de “escuela de formación” en la lucha armada. Así, a través de la exaltación de este vínculo, el reconocimiento de la historia de la guerrilla argentina arrojó un manto de piedad sobre el lugar de gestación de estos movimientos.

En este marco, el presente trabajo tiene como objetivo analizar los cambios en las representaciones sobre este grupo entre los años 1996-2008. Dichos cambios fueron registrados a partir de dos ejemplos de la prensa gráfica masiva (los diarios Clarín y La Nación), una breve síntesis del impacto que Tacuara tuvo en la industria editorial de los últimos años y tres archivos audiovisuales: el filme documental de Luis Barone, Los malditos caminos (2002), el primer capítulo del unitario televisivo $9 \mathrm{~mm}$ sobre el asesinato de Alterman, emitido por el canal de cable Ciudad Abierta (2007) y el especial televisivo del programa Otro tema, "Operación Rosaura: el comienzo de la guerrilla armada”, del canal de cable TN (2007). Asimismo, los cambios de valor de estas representaciones sobre el grupo repercutieron inevitablemente sobre el discurso actual de ex militantes. Con el fin de analizar esta interrelación, se estudian aquí dos testimonios relevados durante el marco temporal elegido, producto de entrevistas propias realizadas a ex miembros de Tacuara. ${ }^{3}$

\section{Sobre Tacuara}

\footnotetext{
${ }^{3}$ El corpus seleccionado constituye una muestra representativa de un universo documental más amplio que por cuestiones de espacio fue recortado en este trabajo. El análisis del corpus documental completo se puede consultar en Galván, 2008. GALVÁN, María Valeria. El Movimiento Nacionalista Tacuara y sus agrupaciones derivadas: una aproximación desde la historia cultural. 2008. Tesis (Maestría en Sociología de la Cultura) — IDAES, Universidad Nacional de San Martin, Buenos Aires, 2008.
}

Revista Eletrônica da ANPHLAC, n.11, p. 8-39, jul./dez. 2011.

http://revista.anphlac.org.br/index.php/revista 
Con la autodenominada Revolución Libertadora, que derrocó al gobierno peronista en 1955, se inicia en la Argentina una etapa de ebullición política. En este contexto marcado por la inestabilidad de una democracia incompleta, la consolidación de la identidad peronista y el impacto de la Revolución Cubana, un conjunto de agrupaciones conformadas por jóvenes católicos y nacionalistas de derecha, conocidas bajo el nombre genérico de Tacuara, protagonizó una serie de atentados políticos de carácter antisemita y anticomunista. Debido a ello, los jóvenes tacuara de ideología nacionalista, corporativista, antisemita, antiliberal y anticomunista, eran vistos por sus contemporáneos como un grupo derechista cercano al fascismo.

Tacuara, representante de una nueva y joven generación de nacionalistas de derecha, había recibido un fuerte influjo del catolicismo, del revisionismo histórico y de los fascismos europeos. Este conjunto heterogéneo de ideologías no sólo cimentó acciones violentas contra comunistas, símbolos liberales e individuos e instituciones judías, sino que también se manifestó en sus rituales, su estética y su iconografía.

Los jóvenes tacuaristas habían comenzado, ya durante su adolescencia temprana, a formarse con las obras de diversos representantes del nacionalismo de derecha de comienzos del siglo veinte. En éstas habían cobrado relevancia las tesis acerca de la necesidad e importancia de los héroes, jefes o caudillos (FINCHELSTEIN, 2002), idea a la que también adhirieron los jóvenes discípulos. Asimismo, el carácter tradicionalista de este conjunto de ideas derivó en la nostalgia por modelos del pasado donde habría reinado el orden y la armonía. En este sentido, reconocían como enemigos principales al liberalismo, a la democracia, al capitalismo, al socialismo y al comunismo, y propugnaban un estado fuerte y eminentemente corporativo (BUCHRUCKER, 1999, NAVARRO GERASSI, 1968, DEVOTO, 2002).

El conglomerado de agrupaciones tacuaristas comienza a formarse en 1960 con la separación — inspirada en el adoctrinamiento del cura Julio Meinveille — de la Guardia Restauradora Nacionalista (GRN) del original Movimiento Nacionalista Tacuara (MNT),

Revista Eletrônica da ANPHLAC, n.11, p. 8-39, jul./dez. 2011. http://revista.anphlac.org.br/index.php/revista 
liderado por Alberto Ezcurra Uriburu. En 1961 se escinde el Movimiento Nueva Argentina (MNA) y en 1963 el Movimiento Nacionalista Revolucionario Tacuara (MNRT).

La primera de estas escisiones respondió a un proceso radicalización de las tendencias derechistas y antisemitas de un sector disconforme con el proceso de "peronización" y ampliación de las bases que experimentó el MNT luego del conflicto "Laica o Libre". ${ }^{4}$ El segundo grupo (MNA) se asimiló al sindicalismo peronista, luego de los intentos fallidos del MNT de infiltrarse en los sindicatos para cooptar sus bases. Luego de la separación, el MNA mantuvo una estrecha relación con la derecha peronista, principalmente a través de la Unión Obrera Metalúrgica (UOM), cuyo dirigente, Armando Cabo, tenía un hijo en este grupo (Dardo Cabo). La agrupación saltó a la fama en 1966, cuando se dieron a conocer los detalles de la "Operación Cóndor", hecho - se caracterizó por mantenerse alejada de las páginas de los diarios.

Por último, el MNRT se separó del MNT por conflictos de poder al interior del grupo original y disidencias ideológicas originadas por las influencias del peronismo de izquierda y la Revolución Cubana. Dirigido por Joe Baxter y José Luis Nell, el nuevo desprendimiento del derechista MNT buscó redefinirse a partir del agregado de "revolucionario" que hacía referencia, particularmente, al cambio radical en sus premisas ideológicas. A diferencia del MNT, que era antiperonista, reaccionario, autoritario y católico, el MNRT se caracterizaba por sus ideas más seculares y — a pesar de seguir adscribiendo al nacionalismo - por ser pro obrerista y por identificarse con la causa peronista. Por estas razones, se unió con organizaciones juveniles de izquierda y con algunos sindicatos al mismo tiempo que repudió a los grupos de extrema derecha, con quienes había compartido ideas y prácticas. Esta Tacuara "revolucionaria", dotada de un particular romanticismo ingenuo, buscaba aprender a dirigir la lucha guerrillera, cuyos

\footnotetext{
${ }^{4}$ Este debate giró en torno a la reglamentación del artículo 28 del decreto 6403/55 que permitía la creación de universidades privadas (principalmente bajo influencia de la Iglesia Católica) habilitadas para emitir títulos oficiales

${ }^{5}$ La operación consistió en el secuestro de un avión, con el fin de llegar a las Islas Malvinas.
}

Revista Eletrônica da ANPHLAC, n.11, p. 8-39, jul./dez. 2011.

http://revista.anphlac.org.br/index.php/revista 
principales modelos eran Cuba y Argelia y, debido a la atención primordial que se prestaba a la praxis política, dejaba en un segundo plano el marco ideológico, por lo que éste se caracterizó por ser confuso y, muchas veces, hasta contradictorio.

Más allá de las diferencias entre el MNT, GRN, MNA y MNRT, “Tacuara” — en general - era conocida por sus simbologías exóticas con reminiscencias nazis y sus numerosos atentados antisemitas. Sin embargo, la opinión pública de su época era bastante benévola con los jóvenes nacionalistas, a quienes muchos veían como adolescentes tardíos que canalizaban el hastío de la clase alta a la que pertenecían a través de ideales políticos.

En este contexto de opinión, el 24 de febrero de 1964, en un plenario de discusión sobre el plan de lucha de la CGT de Rosario llevado a cabo en el Salón de Cerveceros de esa ciudad, se inició un tiroteo entre militantes del MNT de Santa Fe y militantes comunistas, en el que murieron tres personas y hubo numerosos heridos, entre ellos, varios integrantes del MNT (GLÜCK, 2000). ${ }^{6}$ La repercusión de los hechos de Cerveceros alcanzó a todos los comandos del MNT. Fue así como el 29 de febrero un grupo de afiliados de Capital Federal acudió al domicilio de Raúl Alterman — un joven judío, militante izquierdista - y, a modo de represalia, lo asesinaron. Inmediatamente después de este hecho, la prensa estalló con hipótesis y especulaciones acerca del carácter de estas agrupaciones. Los jóvenes miembros de Tacuara eran, aparentemente, hijos de buenas familias, muy bien educados pero rebeldes, que simplemente pasaban el tiempo jugando a los western. ${ }^{7}$ La sorpresa de gran parte de la opinión pública respecto de este hecho, parece soslayar el profundo antisemitismo que - sin embargo - los militantes tacuaristas profesaban y que había inspirado, hasta aquel momento, numerosos atentados y agresiones de todo tipo contra instituciones e individuos de la comunidad judía.

Esta ola de atentados antisemitas se había desencadenado, principalmente, a partir de la captura en Argentina del criminal de guerra nazi Adolf Eichmann por parte de agentes

${ }^{6}$ Consultar también La Nación, 26 de febrero de 1964; La Nación, 27 de febrero de 1964; La Nación, 28 de febrero de 1964; Clarín, 28 de febrero de 1964; Primera Plana, 3 de marzo de 1964.

${ }^{7}$ Consultar Primera Plana, 10 y 17 de marzo de 1964, El Popular, 18 de marzo de 1964, entre otros.

Revista Eletrônica da ANPHLAC, n.11, p. 8-39, jul./dez. 2011.

http://revista.anphlac.org.br/index.php/revista 
del servicio secreto israelí (Mossad) en 1960 y los actos de violencia racial continuaron sin interrupción durante los años siguientes. ${ }^{8}$ Uno de los atentados de contenido antisemita más impactante, debido a que generó fuertes tomas de postura de diversos sectores de la sociedad frente a la ya ineludible problemática del antisemitismo en Argentina, fue el secuestro de la estudiante judía Graciela Narcisa Sirota, en junio de 1962, que fue liberada por los tacuaristas al cabo de varios días, con una cruz esvástica tatuada en su pecho (SENKMAN, 1989).

En contraste con estas experiencias, de la última división de la Tacuara original había surgido en 1963 el MNRT que, liderado por Joe Baxter y José L. Nell, comenzó a inclinarse hacia la lucha armada, a partir de las influencias de la Revolución Cubana y del movimiento de liberación en Argelia (GUTMAN, 2003). Tras el abandono de una posición derechista y antisemita, esta facción de Tacuara propugnaría desde el nacionalismo de izquierda la necesidad de la lucha armada.

Para el MNRT era prioritario conseguir armas para cumplir con su plan y, por ello, emprendieron una serie de asaltos a fábricas de armas y depósitos militares (GUTMAN, 2003, BERAZA, 2005). En el marco de este plan tiene lugar el famoso asalto al camión de caudales en la policlínica bancaria del barrio de Flores de Capital Federal. El 29 de agosto de 1963, un grupo de jóvenes armados, luego de haber secuestrado una ambulancia alquilada, irrumpe en la entrada de la policlínica y asalta al camión de caudales destinado al pago de sueldos. El botín, de 14 millones de pesos, se consiguió a costa de varios heridos y dos muertos. Un año más tarde se descubrió que los verdaderos autores del hecho habían sido miembros del MNRT.

Frente al impacto que ocasionó la noticia del descubrimiento de la autoría del

\footnotetext{
${ }^{8}$ Ver, al respecto: La Luz, 2 de noviembre de 1962; Mundo Israelita, 15 de septiembre de 1962; Nueva Sión, 14 de diciembre de 1962; La Prensa, 22 de enero de 1963; Correo de la Tarde 23 de enero de 1963; Clarín, 23 de enero de 1963; Clarín, 26 de enero de 1963; Nueva Sión, 8 de febrero de 1963; Así, 31 de marzo de 1964; Comisión Provincial por la Memoria (ex archivo DIPBA), Legajo 1609, carpeta Daños, Mesa "DS"; Legajo 1715, carpeta Daños, Mesa "DS"; Legajo 1829, carpeta Daños, Mesa "DS".
}

Revista Eletrônica da ANPHLAC, n.11, p. 8-39, jul./dez. 2011. http://revista.anphlac.org.br/index.php/revista 
cinematográfico y cruento asalto, se vieron modificadas la liviandad y la tibieza con las que hasta el momento se había tratado la problemática Tacuara en la prensa gráfica. Luego de la intervención de Interpol, dos argentinos que estaban viviendo con el dinero marcado del robo a la policlínica fueron hallados en Paris. A raíz de la denuncia de una copera de un cabaret parisino, donde los militantes enviados por el MNRT a Europa para cambiar los billetes robados habían pagado con el dinero marcado, la Policía Federal argentina comenzó a desentrañar las vinculaciones de Tacuara con el asalto. La noticia estalló en las primeras páginas de los diarios más importantes del país, poniendo al MNRT — y en menor medida también al MNT — en el foco del análisis. ${ }^{9}$ Básicamente, se cuestionaba el carácter político de una organización que había asesinado para robar dinero destinado a los sueldos de los trabajadores y que se dedicaba a dilapidar el botín en viajes de lujo, bares y cabarets.

El esclarecimiento del robo al Policlínico Bancario y sus secuelas llamó la atención acerca de la existencia y las particularidades de estos grupos de jóvenes que se hacían llamar nacionalistas, guerrilleros, revolucionarios y hasta peronistas. Luego del asalto al policlínico bancario, Tacuara fue condenada por la opinión pública, principalmente por disfrazar motivaciones personales con fines políticos para cometer delitos comunes. Sin embargo, un año después, la atención de la prensa en Tacuara comenzó a disminuir hasta desaparecer completamente. Igual suerte corrieron las mismas agrupaciones. ${ }^{10}$

Desde la disolución del MNT y el resto de las agrupaciones Tacuara hasta hoy, las

\footnotetext{
${ }^{9}$ La noticia del asalto se puede rastrear en Pregón, 24 de marzo de 1964; Crónica, 25 de marzo de 1964; La Nación, 24 de marzo de 1964; Clarín, 25 de marzo de 1964; El Siglo, 25 de marzo de 1964, Clarín, 26 de marzo, La Voz del Interior, 26 de marzo de 1964, La Nación, 28 de marzo de 1964, Careo del 1 de abril de 1964 y Ocurrió, 10 de abril de 1964.

${ }^{10}$ Según Gutman y Beraza, el MNRT de Baxter había comenzado a dispersarse tras la resolución del asalto, debido a los encarcelamientos y al exilio de la mayoría de sus integrantes. Si bien el MNT también perdió fuerza y prestigio luego del asesinato de Alterman, continuó unido algunos años más. La GRN habría sido disuelta luego de la llegada de Onganía al poder, por coincidencia ideológica con el Gobierno, aunque existen números de su boletín, Mazorca, que datan del año 1971. Finalmente, el MNA fue la única de estas agrupaciones que, debido a su relación con el sector vandorista del sindicalismo peronista, se fortaleció y adquirió mayor protagonismo.
}

Revista Eletrônica da ANPHLAC, n.11, p. 8-39, jul./dez. 2011. http://revista.anphlac.org.br/index.php/revista 
configuraciones de sentido en torno al grupo variaron profundamente en relación a aquellas que habían predominado durante sus años de actividad.

\section{Cambios en los regímenes de memoria: opinión pública y cultura popular}

Luego de dos décadas y media en que la historia de Tacuara permaneció en un segundo plano, el grupo recuperó la centralidad en el discurso periodístico en los años noventa a partir de un informe-denuncia que realiza el semanario Noticias. En el año 1996, la revista denunció que el ministro de justicia de ese momento, Rodolfo Carlos Barra, había pertenecido en su juventud al "grupo filonazi" Tacuara. ${ }^{11}$ Esto, en el contexto de los recientes y traumáticos atentados a la embajada de Israel (1992) y a la sede de la Asociación Mutual Israelita Argentina (AMIA) en la ciudad de Buenos Aires (1994), provocó un escándalo mediático que terminó con la renuncia del funcionario. Cuando su pasado oscuro salió a la luz, Barra declaró que se avergonzaba de haber cometido ese "pecado de juventud", sin embargo, el costo político que la denuncia había implicado, le costó su permanencia en el cargo. ${ }^{12}$ En 1999 resurgió la polémica de este caso, cuando Barra fue nombrado auditor general de la Nación. ${ }^{13}$ Lo interesante de esto no es sólo que la infamia del funcionario traería de vuelta a la memoria de los argentinos la existencia de Tacuara, sino el hecho de que fuese esta filiación juvenil el único punto de su carrera política rotundamente imperdonable para la opinión pública, a pesar de la larga lista de actos de corrupción en el desempeño de sus cargos como funcionario y ministro de justicia,

\footnotetext{
${ }^{11}$ Esto fue publicado en Noticias, 22 de junio de 1996.

${ }^{12}$ Ver La Nación, 6 de agosto de 1996. Dos años más tarde, Barra volvió a declarar al respecto: "fue una situación infantil de la adolescencia [...] yo no era nazi, o bien no sabía que era ser nazi. Pero si tuve una tendencia antidemocrática de desprecio a los partidos. Si bien era un adolescente, el haber tenido una posición autoritaria, visto hoy desde los 50 años, es algo de que avergonzarse [...] eran las tendencias, las modas de la época" (Ver Clarín, 5 de enero de 1998).

${ }^{13}$ Consultar: La Nación, 20 de diciembre de 1999 y Clarín, 14 de diciembre de 1999.
}

Revista Eletrônica da ANPHLAC, n.11, p. 8-39, jul./dez. 2011.

http://revista.anphlac.org.br/index.php/revista 
que los medios de la época le habían imputado. ${ }^{14}$

Sin embargo, observando el contexto histórico en que se insertó este caso, parece que el carácter de imperdonable de su paso por Tacuara - definida sintéticamente en esos años como organización nazi (caracterización que fue confirmada por el ministro mismo ${ }^{15}$ ) - se encuentra estrechamente ligado a las heridas todavía abiertas en el imaginario social, que habían dejado los traumáticos episodios ocurridos en la Argentina en la embajada de Israel y en la AMIA, sumadas al recuerdo de la gran cantidad de desaparecidos judíos durante la última dictadura y a la voluntad de limpiar toda imagen que vinculara al peronismo con el fascismo y el nazismo, como parte del realineamiento del gobierno del presidente Carlos Menem con Estados Unidos. En este marco, no parecía prudente dejar las investigaciones de estos atentados contra la comunidad judía cometidos en la década de los noventa en manos de un ministro de justicia que había sido un nazi confeso en su juventud.

Más allá de la valoración exclusivamente negativa que recayó sobre Tacuara a partir de esta denuncia periodística, no es un dato menor la asociación que se estableció entre "haber militado en Tacuara" y cargar con un "pasado vergonzoso". Este pasado oscuro, se correspondía también - en el caso Barra - con un presente cuestionado. En este sentido, la cadena de asociaciones establecida a partir de las particularidades del caso sería rápidamente generalizada hacia todos aquellos que hubiesen militado en alguna de las agrupaciones Tacuara. Asimismo, otro elemento que más tarde cobraría relevancia es la búsqueda de exculpación en la juventud.

A partir de este estruendoso retorno de Tacuara a los medios gráficos ya no se olvidaría mencionar la participación nefasta del grupo nacionalista, antisemita y de ultraderecha durante la década de los sesenta. Los ejemplos más resonantes de esto fueron el aniversario de los 65 años de la fundación de la Delegación de Asociaciones Israelitas

\footnotetext{
${ }^{14}$ Ver, por ejemplo, La Nación, 20 de diciembre de 1999.

${ }^{15}$ Según la nota de la revista Noticias, Barra declaró a través de su vocera: "si fui nazi en mi juventud, me arrepiento" (Noticias, 22 de junio de 1996).
}

Revista Eletrônica da ANPHLAC, n.11, p. 8-39, jul./dez. 2011. 
Argentinas (DAIA) ${ }^{16}$ y el desbaratamiento de una banda de criminales que robaba cajas de seguridad en el año 2001; uno de cuyos miembros era Horacio Rossi, ex militante del MNT y del MNRT, partícipe del asalto al policlínico bancario en 1963. Esta última noticia es titulada por La Nación con una aseveración que no deja lugar a dudas: "Rossi: casi 40 años de historia criminal. Su primer gran golpe lo dio en el año 1963". ${ }^{17}$ Este hecho también contribuyó a recuperar discursivamente el costado eminentemente criminal de Tacuara que había imperado en los sesenta, luego del asalto al políclinico. En este sentido, la actualidad parecía confirmar las aseveraciones que la prensa gráfica había realizado al respecto en aquel entonces. Sin embargo, aparece una diferencia: estas representaciones sobre las actividades delictivas del ex tacuara se presentan en los medios como parte del comienzo de un largo y doloroso preludio de la situación actual del país, en donde se intentaría develar el carácter verdadero de este personaje. Así, la noticia recuerda que

Lejos de ser un delincuente común o, mejor dicho, un ladrón de estos tiempos, Horacio Francisco Rossi es un nexo con los más violentos días de los agitados años sesenta y setenta [...] Rossi participó del primer golpe criminal destinado a financiar las operaciones de un grupo extremista en nuestro país: integró la célula de la agrupación ultranacionalista Tacuara que el 29 de agosto de 1963 copó el Policlínico Bancario en Caballito, y que antes de escapar con su botín de casi 14 millones de pesos de la época -el dinero destinado al pago de sueldos- causó la muerte de dos personas y heridas a otras tres [...] [Tacuara] fue a los sesenta lo que sería para principios de la siguiente década la Triple A $\left[\ldots . .{ }^{18}\right.$

Un año después, la muerte de Rodolfo Galimberti ofreció una nueva excusa para remarcar estas representaciones sobre Tacuara. El controversial personaje ${ }^{19}$ fue tomado

\footnotetext{
${ }^{16}$ La DAIA había sido la principal entidad denunciante de los actos antisemitas perpetrados por Tacuara en la década del sesenta. Sobre esto, consultar, por ejemplo, Clarín, 28 de octubre de 2000.

${ }^{17}$ Publicado en La Nación, 25 de abril de 2001.

${ }^{18}$ Publicado en La Nación, 25 de abril de 2001.

${ }^{19}$ Rodolfo Galimberti, luego de su militancia en Tacuara, llegó a Montoneros. Después del triunfo de Héctor Cámpora en el 1973, Galimberti -como delegado de la Juventud Peronista- llamó a la creación de milicias armadas para defensa de la democracia. Cuando esto se hizo público, Perón lo convocó a Madrid para destituirlo de su puesto en la Juventud Peronista. En Montoneros participó de numerosos atentados y secuestros. Uno de los secuestros más resonantes fue el de los empresarios Born. Con el advenimiento de la
}

Revista Eletrônica da ANPHLAC, n.11, p. 8-39, jul./dez. 2011.

http://revista.anphlac.org.br/index.php/revista 
como una especie de muestra de lo que heredó el país de la militancia de esa época. Sin embargo, tampoco se dejó pasar por alto que su nacimiento a la vida política y pública fue de la mano de Tacuara:

Galimberti, más conocido como Galimba o El Loco, personificó muchos de los males que aquejaron a la Argentina de las últimas tres décadas: el fin de las utopías, la celebración de la violencia, la apología de la tortura, la incoherencia, el arribismo, los pactos espurios, la cultura light, la sed de poder, el egocentrismo, la ausencia total de autocrítica [...]

Arrancó su actividad política a los 16 años en el grupo nacionalista Tacuara, donde aprendió a tirar sus primeras bombas molotov en los albores de la década del $60 .^{20}$

\section{Sobre sus comienzos en Tacuara, Clarín agrega que Galimberti}

Fue, como todo el embrión de la guerrilla montonera de los 70, católico y de derechas. Apenas entrado en la adolescencia, y cuando los años 60 aún no se habían convertido en turbulentos, militó en el grupo nacionalista Tacuara, cuyos integrantes más jóvenes solían lucir el pelo engominado, un remedo de cruz de hierro hitleriana como llavero y una patética escasez de ideas. ${ }^{21}$

Es decir, la biografía de este personaje tan paradigmático de la historia argentina comprobaba para la opinión pública la bajeza moral y la superficialidad ideológica de Tacuara, agrupación nacionalista de ultra-derecha, nazi y pobre de ideas e ideales. Asimismo, como bien muestra la cita de arriba, fue usual en los medios utilizar estas

dictadura en 1976 se exilió en Brasil, en Méjico y finalmente en Paris. En 1979 se alejó de Montoneros por disentir con su alta dirigencia. A su regreso al país, en 1989 con el indulto del entonces presidente de la Nación, Carlos Saúl Menem, se asoció con Jorge Born (a quien había secuestrado en los setenta) y pasó a integrar las filas de la clase empresarial de los noventa. Durante esta época, en la que también se involucró con la farándula y fue uno de los abanderados de la frivolidad predominante en esos ámbitos, se arrepintió de su pasado militante, adhiriéndose implícitamente a la teoría de los dos demonios al opinar que tanto el gobierno militar como la guerrilla cometieron excesos por igual. También en este momento entabló amistad con ex torturadores de la dictadura. Asimismo, siempre cercano al menemismo, fue nombrado asesor de la SIDE debido a que, aparentemente, comercializaba servicios de espionaje e inteligencia para Francia, primero, y para la CIA, posteriormente (Ver La Nación, 13 de febrero de 2002, Clarín, 13 de febrero de 2002 y Larraquy y Caballero, 2000).

${ }^{20}$ Publicado en La Nación, 13 de febrero de 2002.

${ }^{21}$ Publicado en Clarín, 13 de febrero de 2002.

Revista Eletrônica da ANPHLAC, n.11, p. 8-39, jul./dez. 2011.

http://revista.anphlac.org.br/index.php/revista 
caracterizaciones sobre Tacuara para descalificar a las agrupaciones de izquierda de la década de los setenta, formadas con muchos ex tacuaristas.

Sin embargo, las connotaciones negativas en la prensa gráfica sobre Tacuara comenzarían a relativizarse a partir del cambio producido en la política de derechos humanos y memoria de parte del gobierno nacional, que terminaría beneficiando indirectamente la memoria popular sobre este grupo.

Los regímenes de memoria ${ }^{22}$ referentes a la dictadura ya habían sufrido un quiebre en el año 1995, con la confesión pública del ex capitán de corbeta Adolfo Scilingo acerca de su participación en los "vuelos de la muerte". A esto le siguió la "autocrítica" del jefe del Ejército en aquel momento, teniente general Martín Balza. Este escándalo interrumpió la marginalidad a la que la denuncia por las violaciones a los derechos humanos y la memoria de las agrupaciones de izquierda de los setenta estuvieron relegadas durante la primera mitad de la década de los noventa. ${ }^{23}$ Esta reapertura del debate público acerca del terrorismo de estado de los setenta en 1995 comenzaría gradualmente a cambiar las tendencias discursivas al respecto. En el año 2003 se inició el mandato presidencial de Néstor Kirchner, quien relevó la cúpula militar y se pronunció a favor de la nulidad de las leyes de Obediencia Debida y Punto Final, impulsando su tratamiento en la Corte Suprema. Durante su gobierno se anuló el decreto que impedía las extradiciones de represores, se designó a Eduardo Luis Duhalde como Secretario de Derechos Humanos, y su política recibió el apoyo de organismos de Derechos Humanos, entre ellos las Madres de Plaza de Mayo (LVOVICH Y BISQUERT, 2008).

El 24 de marzo de 2004 se retiraron del Colegio Militar de la Nación los retratos de

\footnotetext{
${ }^{22}$ Concepto acuñado por Emilio Crenzel y definido como "aquellas 'memorias emblemáticas' que se tornan hegemónicas en la escena pública al instaurar, a través de prácticas y discursos diversos, los marcos de selección del lo memorable y las claves interpretativas y los estilos narrativos para evocarlo, pensarlo y transmitirlo" (CRENZEL, 2008, p. 24).

${ }^{23}$ Como sostienen Lvovich y Bisquert, "con los decretos de indulto del presidente Carlos Menem se pretendió clausurar el pasado para dar inicio a una etapa definida como de 'pacificación nacional' [...] en momentos en que la problemática el terrorismo de estado atraviesa un relativo debilitamiento de su presencia en la esfera pública" (LVOVICH Y BISQUERT, 2008, p. 7-8).
}

Revista Eletrônica da ANPHLAC, n.11, p. 8-39, jul./dez. 2011.

http://revista.anphlac.org.br/index.php/revista 
los ex dictadores Jorge Rafael Videla y de Leopoldo F. Galtieri y se celebró un acto en la Escuela de Mecánica de la Armada (ESMA), en el cual Kirchner pidió disculpas públicas de parte del estado nacional y anunció el objetivo de construir allí un museo de la memoria en presencia de ex detenidos que habían pasado por ese centro clandestino de detención y tortura. Esta recuperación de la militancia revolucionaria contribuyó a una mistificación de la tradición setentista que incluía las trayectorias de las agrupaciones revolucionarias (Juventud Peronista, Montoneros, ERP, etc.) (LVOVICH Y BISQUERT, 2008). Asimismo, en el año 2006 se reeditó el Nunca Más con un nuevo prólogo firmado por la Secretaría de Derechos Humanos de la Nación (CRENZEL, 2008).

En este sentido, el cambio en las políticas de la memoria, cuyo gesto más emblemático fue la creación del museo de la ESMA, habilitó la reivindicación de la historia y la lucha de las organizaciones armadas de la década de los setenta y Tacuara se vio favorecida con ello, por extensión, ya que comenzó implícitamente a ser considerada como una agrupación "preparatoria" o de "formación” de quienes más tarde militaron en las agrupaciones guerrilleras de izquierda (principalmente en Montoneros), por lo que la mayoría de ellos resultaron víctimas del terrorismo de estado durante la última dictadura militar (1976-1983). Dentro de este marco, proliferaron los relatos bibliográficos y cinematográficos que presentaban un costado diferente de Tacuara.

Así, despertando gran interés en el público lector, aparecieron dos nuevas narraciones históricas acerca de los jóvenes tacuaristas: los libros del periodista Daniel Gutman (2003) y del ex militante Roberto Bardini (2002). La importante difusión que tuvieron (desde narrativas y posturas ideológicas diferentes, como se intentará demostrar) los libros de Gutman y Bardini se encuadran en el contexto del giro producido en los gustos de los consumidores culturales en la Argentina de la pos-crisis hacia lecturas históricas no académicas y biografías de figuras históricas. Este cambio en las preferencias de los lectores argentinos — producto de la insatisfacción generalizada ante la situación política heredada de la crisis económica, política e institucional del 2001 - da cuenta de una

Revista Eletrônica da ANPHLAC, n.11, p. 8-39, jul./dez. 2011.

http://revista.anphlac.org.br/index.php/revista 
búsqueda de explicaciones al "fracaso nacional" del momento en los relatos históricos (Semán, 2006). En este marco de búsqueda de sentidos en la historia nacional para comprender un presente problemático - que se complementa, a su vez, con el cambio en los regímenes de memoria del pasado reciente - la historia de las agrupaciones Tacuara adquieren un nuevo brillo que encarna en los libros de Gutman y Bardini.

El primero de ellos, basado en la investigación periodística realizada por Daniel Gutman sobre la historia del conglomerado de agrupaciones Tacuara, enfatiza que Tacuara fue la "primera guerrilla urbana" en la Argentina. En este sentido, el autor encuentra que “quizá como ningún otro grupo, Tacuara expresó el drama de la Argentina de comienzos de los sesenta, dueña de una democracia sólo formal y con las Fuerzas Armadas en el centro del poder. La época en que apenas amanecía la violencia que explotó en los setenta" (GUTMAN, 2003, p. 19). Con esta tesis como fondo, Gutman se dedica a realizar un análisis pormenorizado de las fuentes existentes sobre el grupo Tacuara. Así, trabaja con entrevistas a los actores principales de la época, expedientes judiciales y, principalmente, diarios y revistas contemporáneas y órganos de difusión de los militantes. No obstante esta vinculación que establece entre los jóvenes nacionalistas y el origen de la violencia política de la historia Argentina, Gutman no deja de recuperar - a través del relato de anécdotas personales - una Tacuara que, más allá de sus afiliaciones de extrema derecha, es presentada como más humana.

En este mismo sentido, la memoria del ex miembro tacuarista, Roberto Bardini, intentó mostrar el costado subjetivo de la militacia en el MNT y en el MNRT. La autobiografía autoexculpatoria de Bardini, a pesar de su carácter pionero en recuperar desde el mercado editorial la historia de Tacuara (su primera y única edición es del año 2002), tuvo menor repercusión que la investigación periodística de Gutman. Pese a ello, el valor principal del libro de Bardini radica en que éste es el primer testimonio escrito hecho público por un ex Tacuara. Así, esta obra pretende transformar la memoria colectiva que asocia a Tacuara con valores tales como el catolicismo, antisemitismo, extremismo político

Revista Eletrônica da ANPHLAC, n.11, p. 8-39, jul./dez. 2011. http://revista.anphlac.org.br/index.php/revista 
(tanto de derecha como de izquierda) y nacionalismo; es decir que propone una revisión de una Tacuara, según el autor, estereotipada (y estigmatizada) por la opinión pública, desde el lugar de lo autobiográfico. Este esfuerzo resulta en una versión de Tacuara desnazificada. De este modo, Bardini se distancia (como ex miembro del MNT y del MNRT) de la Tacuara nazi, fascista, católica e hispanista.

De la misma manera, numerosos guiños de su relato dejan leer entrelíneas la sugerencia acerca de la existencia de una Tacuara "de derecha" (muy políticamente incorrecta) a la que se contrapuso una segunda Tacuara, que se ve exculpada, en última instancia, por sus filiaciones con el peronismo de izquierda y su carácter de víctima de la última dictadura militar. Así, se pueden leer títulos tales como "Un Tacuara - como muchos - que no leyó a Hitler ni pintó svásticas", "24 de marzo de 1976: la primera víctima, un nacionalista” o "El 'pecado' nacionalista”, junto a epígrafes como el de Edgar Morin:

Hace poco, me preguntaron: ‘¿Usted sabía que Emile Cioran, cuando joven, era nazi? Guardia de Hierro en Rumania'. Y contesté: 'Sí, es horrible, pero no es posible reducir a alguien a su pasado, a su juventud. Lo cierto es que evolucionó después (BARDINI, 2002, p. 153).

En este contexto, Bardini enfatiza, a modo de justificación, en la heterogeneidad ideológica de Tacuara y clarifica:

\footnotetext{
¿Hubo entre los integrantes de Tacuara simpatizantes de Hitler y Mussolini?: sí, pero en su etapa inicial y no todos lo fueron ¿Fue Tacuara anticomunista?: sí, pero no hay que olvidar la trayectoria del desprestigiado Partido Comunista Argentino [...] ¿Fue Tacuara una organización antisemita?: sí, pero en el transcurso del tiempo la mayor parte de sus militantes abandonó esa postura [...] El racismo no es patrimonio de los nacionalistas (BARDINI, 2003, p. 158).
}

El patrón clave de este discurso (JAMES, 2004) es la toma de distancia del narrador del militante de Tacuara prototípico en la opinión pública hasta este momento. Recordando

Revista Eletrônica da ANPHLAC, n.11, p. 8-39, jul./dez. 2011. http://revista.anphlac.org.br/index.php/revista 
que el patrón clave da cuenta de la relación del narrador con los modelos sociales dominantes, es posible que el testimonio de Bardini se encuentre ya influenciado por la incipiente política de derechos humanos que posibilitaría la reivindicación de los pasados militantes. En este marco, Bardini se presenta a sí mismo como un arrepentido por el pasado vergonzoso del primer MNT, pero esto queda en un segundo plano frente a su rol de “justiciero" o "reparador". Es decir, en su relato, el autor ocupa el rol de quien denuncia las infamias contra militantes de Tacuara, que "no leían a Hitler" y que más tarde caerían víctimas de la represión estatal.

Las notas periodísticas que promocionaban estos libros ${ }^{24}$ testimoniaron las repercusiones que tanto el cambio en los regímenes de la memoria como el quiebre en el gusto de los lectores de no-ficción tuvieron en las representaciones sobre Tacuara. En estos artículos tan sólo se describían las hipótesis y los recorridos narrados en los libros de Gutman y Bardini, pero estas simples referencias obligaron al discurso de la prensa gráfica a ir más allá de las aseveraciones obvias y pobremente fundamentadas que simplificaban a las agrupaciones Tacuara presentándolas como un homogéneo grupo nazi y de ultraderecha. De esta manera, comenzó a renovarse el interés de la opinión pública por los vaivenes de esta oscura agrupación política de la que el sentido común de la sociedad de ese momento sabía muy poco.

El interés por Tacuara siguió manifestándose en las librerías. Al éxito editorial de los libros de Gutman y, en menor medida, de Bardini, se le sumaron en el año 2006 los libros Joe Baxter. Del nazismo a la extrema izquierda. La historia secreta de un guerrillero, de Alejandra Dandan y Silvina Heguy, y Manuscrito de un desaparecido en la ESMA. El libro de Jorge Caffatti, de Juan Gasparini, ambas biografías de ex-dirigentes del MNT y del MNRT que luego virarían hacia la militancia de izquierda en los setenta. En la biografía de las periodistas Dandan y Heguy sobre Joe Baxter, la militancia en Tacuara

\footnotetext{
${ }^{24}$ Ver, por ejemplo, Clarín, 11 de mayo de 2003, 10 de junio de 2003 y 29 de agosto de 2003; La Nación, 16 de noviembre 2003.
}

Revista Eletrônica da ANPHLAC, n.11, p. 8-39, jul./dez. 2011.

http://revista.anphlac.org.br/index.php/revista 
ocupa el lugar de los comienzos políticos intempestivos — por el lado de la derecha — de una figura emblemática de los inicios de la violencia política, que se redime a sí mismo con su pasaje hacia el extremismo de izquierda.

Por otro lado, las memorias de Caffatti - escritas durante su cautiverio en la Escuela de Mecánica de la Armada (ESMA) —, introducidas y recuperadas por Gasparini, destacan su temprana militancia en el MNT, el asalto al policlínico bancario como integrante del MNRT, su adhesión a las Fuerzas Armadas Peronistas, la participación en el secuestro del director de la Fiat, Luchino Revelli-Beaumont, en Paris y, finalmente, su cautiverio, torturas y muerte en la ESMA. En este sentido, el relato marca un continuo que asimila el destino individual con el transcurrir del destino del país. Estas memorias, que sobrevivieron a pesar de las condiciones en las que fueron producidas y del destino trágico de su autor, están fuertemente signadas por las condiciones represivas de su producción pero, sobre todo, conllevan la marca de la profunda internalización del compromiso político y social que experimentaba Caffatti en ese momento de su vida. Pese al tono profundamente autocrítico del manuscrito editado por Gasparini, se destaca como patrón clave la convicción de que todas las experiencias pasadas (incluyendo su militancia tacuarista) habrían de capitalizarse en la persona de Caffatti, permitiéndole alcanzar uno de los más altos escalafones del militante ideal: el de mártir.

Finalmente, en el año 2008 se publica el más reciente libro sobre este grupo, basado en la tesis de licenciatura de Juan Esteban Orlandini sobre el Movimiento Nacionalista Tacuara. El autor, que había estado relacionado en su juventud con el $\mathrm{MNT}^{25}$, pretende con este libro que "Tacuara, fuera del discurso 'oficial', hable por sí misma” (ORLANDINI, 2008, p. 23). En este sentido, también como Bardini, desde un punto de vista subjetivo y comprometido personalmente con el objeto, propone revisar la memoria hegemónica sobre el MNT y de este modo postular una versión "auténtica" de lo ocurrido con este grupo. Así,

\footnotetext{
${ }^{25}$ En el prólogo, se aclara que Orlandini había pertenecido a esta agrupación, pero no se especifica si participó como afiliado o simpatizante.
}

Revista Eletrônica da ANPHLAC, n.11, p. 8-39, jul./dez. 2011. 
el autor se esfuerza por mostrar a un militante romántico que sólo lucha por su ideal. En esta travesía narrativa, Orlandini presenta a una Tacuara heroica, más emparentada con la guerrilla de la década posterior que con los nacionalismos de derecha europeos.

Luego de la promoción de los libros mencionados, Tacuara regresa a las páginas de los diaros en el 2008, sin asociaciones valorativas de ningún tipo y en relación a una noticia de derechos humanos. Se trata de uno de los últimos nietos que, habiendo sido apropiado ilegalmente durante la dictadura de 1976, fue recuperado gracias a las labores realizadas por la Asociación de Abuelas de Plaza de Mayo y otras entidades defensoras de los derechos humanos. Los medios que relataron esto recordaron que el padre del nieto Jorge Guillermo Goya había sido el desaparecido Franciso Goya, militante de la Juventud Peronista, Montoneros y del MNT. ${ }^{26}$ La filiación al MNT de Goya no recibió esta vez ningún calificativo negativo.

Además de las producciones bibliográficas y de los discursos de los medios, hubo cuatro audiovisuales argentinos que tuvieron a Tacuara como protagonista y reflejan de igual manera los efectos de las transformaciones de los regímenes de memoria en los discursos sociales sobre los jóvenes tacuaristas.

La primera de ellas es el filme documental Los malditos caminos, de Luis Barone. ${ }^{27}$ Este documental expositivo (NICHOLS, 1997) se encuentra estructurado en base a tres historias de vida. El relato es guiado por una voz omnisciente que cuenta la historia de tres valientes jóvenes idealistas y progresistas, íntimamente relacionados con el peronismo de izquierda en los años setenta y que sufrieron muertes trágicas, uno de los cuales fue José Luis Nell, dirigente del MNRT, que había participado en el asalto al policlínico, estuvo en contacto con los Tupamaros en Uruguay y finalmente se unió a las Fuerzas Armadas Peronistas (FAP) y a Montoneros.

La voice-over de este documental entrelaza testimonios orales de familiares, amigos

\footnotetext{
${ }^{26}$ La noticia de la recuperación de este nieto fue publicada primeramente en La Nación, 31 de julio de 2008.

${ }^{27}$ Estrenada directamente en DVD el 14 de noviembre de 2002; copia color y una duración de 200 minutos.
}

Revista Eletrônica da ANPHLAC, n.11, p. 8-39, jul./dez. 2011.

http://revista.anphlac.org.br/index.php/revista 
y conocidos. Este uso de entrevistas en documentales persigue el objetivo de evocar la emoción del espectador a partir de la memoria del protagonista (ROSENSTONE, 1997). Los malditos caminos hace uso de este recurso con el objetivo de "revivir" las biografías de los protagonistas. Para ello, utiliza en su argumentación una retórica basada principalmente en pruebas emocionales: testimonios que apelan a una empatía del espectador, imágenes de archivo de noticiarios de la época o películas para ilustrar el contexto histórico en que se sucedieron los hechos descriptos y para enfatizar determinados puntos temáticos que terminarían reforzando la argumentación del filme. Los relatos biográficos así construidos y la sobreabundancia de materiales de archivo - ambas estrategias puestas en práctica con un claro fin probatorio de la tesis del realizador - arrojan un manto de objetividad y credibilidad sobre la historia de estos héroes trágicos de la militancia setentista.

En el documental, Tacuara aparece siempre en relación a Nell y, más específicamente, a sus comienzos como militante. En este sentido no se escatiman esfuerzos ni recursos para justificar a nivel individual aquellas acciones de Tacuara como agrupación que habían sido y que aún eran reprochables. Así, a través de entrevistas a ex militantes de la Juventud Peronista, de las Fuerzas Armadas Peronistas y de Tupamaros (todos amigos o compañeros, en algún momento, de Nell) se describe la militancia en Tacuara de una manera tan difusa que muchas veces en las entrevistas hasta se logran confundir las características del MNT y el MNRT con las de la Juventud Peronista y las Fuerzas Armadas Peronistas. Algunas apreciaciones sobre Tacuara parecen buscar justificar el antisemitismo y las simpatías nazis del MNT a través de la "diversidad ideológica” del grupo.

El asalto al policlínico protagonizado por el MNRT en 1963, en el cual Nell fue el único autor de los disparos que causaron las muertes de los trabajadores, es descripto con mucho detalle. También aquí se recurre por fin a los testimonios personales y subjetivos de ex militantes del MNT y del MNRT, quienes minimizan la participación de Nell en el hecho. Finalmente, la fuga de Nell cierra este primer ciclo épico e inicia la nueva y difícil

Revista Eletrônica da ANPHLAC, n.11, p. 8-39, jul./dez. 2011.

http://revista.anphlac.org.br/index.php/revista 
etapa en su vida: el camino de la clandestinidad y del compromiso con el movimiento peronista que lo terminaría consagrando como héroe. Con esto, a través de la adopción de la estructura narrativa de la novela ${ }^{28}$, el discurso fílmico de Barone adhiere a la tesis que comenzaba a emerger en aquel momento acerca de Tacuara, la cual era vista como una suerte de "limbo preparatorio" del camino plagado de pruebas que habría de recorrer el héroe para su redención.

La película revela las creencias, intenciones y el imaginario de la sociedad en que es realizada. ${ }^{29}$ En este sentido, las pretensiones de objetividad y veracidad de lo sostenido por el filme se encuadran también en el marco de referencia general que comenzaba a imponerse en el país, de reivindicación de las luchas populares setentistas y que prepararía el terreno para la implementación de las nuevas políticas sobre derechos humanos.

Más cercano en el tiempo (con este marco de referencia generalizado y también legitimado), el 26 de abril del año 2007 se estrena un corto televisivo para un ciclo de ficción de un canal de cable sobre el asesinato de Raúl Alterman. El ciclo, titulado $9 \mathrm{~mm}$, dedicaba cada capítulo a un crimen político resonante de la historia argentina. El caso Alterman protagonizado por el MNT en 1964 es el primer episodio. Con idea y guión de Marcelo Larraquy y dirigido por Ulises Rossel, el filme parte del punto de vista de los victimarios. Así, relata las motivaciones, inseguridades, e infantilismos en un grupo reducido de tacuaras porteños que quieren vengar la muerte de sus últimos mártires, caídos en el enfrentamiento en el Salón de Cerveceros de Rosario, en 1964. El unitario da cuenta de una mirada eminentemente subjetiva, desarrollada desde la perspectiva de quienes cometieron el crimen (Noticias, 14 de junio del 2007). Al respecto, el autor reconoce que

Iluminar el punto de vista del asesino es incómodo, pero permite ver otras cosas, lo que se juega en la consciencia de cada uno. A muchos, matar los angustiaba. Pero era un compromiso que habían asumido. Un compromiso doloroso que se

\footnotetext{
${ }^{28}$ En este sentido, los tacuaristas se transforman, bajo su mirada, en héroes conflictuados en busca de sentido.

${ }^{29}$ Existen numerosos trabajos que desarrollan la metodología del análisis fílmico como agente de la historia. En particular, se recomienda consultar las obras de Marc Ferro (2000) y Siegfried Kracauer (2002).
}

Revista Eletrônica da ANPHLAC, n.11, p. 8-39, jul./dez. 2011.

http://revista.anphlac.org.br/index.php/revista 
tomaba como una misión. Los asesinos no eran gurkas sanguinarios. Eran tipos de carne y hueso que tenían un problema a resolver (Clarín, 25 de abril del 2007).

Esta representación de Tacuara hubiese sido imposible diez años antes de esa fecha, ya que la perspectiva del asesino, con coloridas inseguridades, miedos e idealismos, propone un acercamiento subjetivo del espectador. Pero, por otra parte, al igual que Los malditos caminos, este episodio de $9 \mathrm{~mm}$ plantea la cuestión acerca del tipo de realidad histórica reconstruida. Esta es una realidad prácticamente opuesta a la que predominó durante los años noventa. Mientras que en aquella época quienes eran considerados por la opinión pública miembros corruptos de la gestión menemista tenían un oscuro pasado nazi, la realidad que plantean estos filmes es la de unos muchachos idealistas, un poco confundidos, llenos de miedos e inseguridades (como "cualquiera de nosotros") que cometieron "errores". Los materiales audiovisuales analizados aquí no sólo dan cuenta de una forma de ver la historia de Tacuara, sino que - desde el momento en que reconstruyen, a partir de los discursos sociales subyacentes, una versión del pasado contribuyen también a crearla, a modificarla.

Sin embargo, estas nuevas representaciones de los jóvenes tacuaristas como jóvenes idealistas, son contrastadas con las representaciones coexistentes en la sociedad, que continúan demonizándolos. Un ejemplo de esto es un especial sobre el asalto al Policlínico, emitido tan sólo unos meses después que el unitario de $9 \mathrm{~mm}$. El 26 de junio de 2007 se emite por el canal de cable $T N$, en el programa Otro Tema, un especial de cuarenta minutos de duración, titulado "Operación Rosaura: el comienzo de la guerrilla urbana". Este documental televisivo, también de modalidad expositiva, presenta el suceso del asalto al Policlínico como la "presentación en sociedad del grupo Tacuara", un "grupo de derecha que marcó el comienzo de la guerrilla urbana". De esta manera, la voice-over del relato va guiando al espectador en el desarrollo de la "historia del grupo Tacuara". Con el fin de legitimar la narración del caso, se citan en el estudio a periodistas entendidos en el tema para que den su opinión especializada. Durante estos testimonios, corren imágenes fijas

Revista Eletrônica da ANPHLAC, n.11, p. 8-39, jul./dez. 2011.

http://revista.anphlac.org.br/index.php/revista 
documentales de fondo que muestran recortes de diario de aquel momento sobre el caso del Policlínico y otros casos protagonizados por Tacuara. Luego de los primeros cuatro minutos de consolidación de un discurso objetivo que diese cuenta de la seriedad del relato, se comienza a intercalar testimonios de ex miembros del MNT. En éstos, se enfatiza en la juventud y en el idealismo que los movilizaba, a la vez que se percibe un esfuerzo por aclarar que no eran "ni de derecha, ni de izquierda", tan sólo nacionalistas. Cumpliendo con su apariencia de objetividad, el programa confronta este discurso de inocencia de los ex militantes tacuaristas con una de las opiniones especializadas que recuerda los atentados antisemitas (las imágenes de fondo acompañan esto con fotos de pintadas de cruces esvásticas firmadas por Tacuara), pero aclara que el peor de todos los crímenes cometidos por Tacuara es el asalto al Policlínico. Así comienza la narración propiamente dicha de este caso.

Este adopta el formato de "novela policial" y en el mismo tono se detalla el crimen. En esta etapa del relato se incorpora también el testimonio de un testigo de la época. También aquí se busca ilustrar lo presentado por el audio con imágenes documentales del edificio del Policlínico, entre las que se cuelan escenas actuales del mismo establecimiento, todas ellas en blanco y negro. Con esto se pretende, por un lado, fortalecer la verosimilitud del relato y, por otro, reafirmar una cercanía con el caso que necesariamente debe ser montada, debido a la distancia temporal entre la cotidianidad del espectador y el momento en que sucedieron los hechos. De modo similar a como fue presentado por la prensa gráfica de aquella época, se cierra el caso con la espectacular fuga de Nell del Palacio de Justicia, lo cual es una oportunidad que el narrador aprovecha para relatar la leyenda de José Luis Nell. El informe documental cierra con la aseveración de uno de los especialistas de que Tacuara era nazi y con un primer plano de la carátula (con reminiscencias icongráficas nazis) del órgano oficial de difusión del MNT, el periódico Ofensiva.

Esta narración del caso abre dos interrogantes para el espectador. En primer lugar, la pregunta acerca de la causa de la comisión de un delito de esas características (donde se

Revista Eletrônica da ANPHLAC, n.11, p. 8-39, jul./dez. 2011.

http://revista.anphlac.org.br/index.php/revista 
robó el sueldo de trabajadores y se mató a inocentes). El segundo interrogante es qué fue del destino de los protagonistas del hecho. Ambos hallan en este relato la misma respuesta: la lucha armada. Es decir, el robo se cometió, como concluye el presentador del programa, con el único fin de recaudar fondos para la "preparación de la propaganda armada" y esta misma sería la causa de disolución del grupo, ya que la mayoría de sus integrantes, luego de caer en la clandestinidad en 1963, se dispersan en los diferentes "bandos" que habrían de enfrentarse durante la década siguiente. En este sentido, el presentador concluye: "Se llamó Operación Rosaura. Inauguró una etapa que culminaría con el horror que todos vivimos en la noche más negra que debimos superar todos los argentinos".

En primer lugar, es interesante destacar que en ningún momento se discrimina entre las diferentes organizaciones Tacuara, ni se hace mención de la existencia de ninguna de ellas. Al igual que los medios de la época, este programa no sólo no reconoce las escisiones sufridas por el MNT original, sino que asimila características del MNT (simpatías con el nazismo, antisemitismo) con el MNRT (agrupación que se había alejado de las ideas antisemitas y de extrema derecha, para comenzar a acercarse a la izquierda peronista), verdadero autor del asalto a la Policlínica. En segundo lugar, al igual que la memoria hegemónica actual, coincide en reconocer a Tacuara como antecesor inmediato de las guerrillas de los setenta, pero esto no contribuye a la construcción de un relato épico acerca de Tacuara, sino, por el contrario, en el marco de una estructura narrativa de novela policial, es utilizado como un argumento más para condenarla.

\section{La memoria de los ex militantes}

Los vaivenes discursivos de la opinión pública generalizada acerca de la historia de Tacuara y sus militantes afectaron los relatos actuales de ex miembros de Tacuara, debido a

Revista Eletrônica da ANPHLAC, n.11, p. 8-39, jul./dez. 2011.

http://revista.anphlac.org.br/index.php/revista 
que estos se estructuraron en forma de respuesta a las aseveraciones públicas acerca de su militancia. Para entender esta interacción dialógica es necesario recordar que los relatos acerca del pasado reciente sólo pueden ser leídos a través de la lente de la memoria. Es decir, el acceso al pasado a través de la subjetividad es necesariamente interceptado por las representaciones presentes acerca de aquel (JELIN, 2007). En este sentido, los testimonios de los ex-militantes de Tacuara analizados en este apartado son considerados en relación al contexto socio-político y cultural en que son producidos, sin olvidar sus posibles intereses y expectativas individuales presentes. Con el fin de observar las representaciones subjetivas actuales sobre Tacuara de sus ex militantes, se realizaron dos entrevistas en profundidad y semiestructuradas a ex integrantes del MNT (uno de los cuales también formó parte del MNRT).

En el caso de los testimonios orales, a las expectativas y valoraciones del presente se le agregan los prejuicios acerca del discurso representado por el entrevistador y las representaciones acerca de sus expectativas, pensando en la comunidad como segundo interlocutor. Por esta razón, el ejercicio de la historia oral exige distinguir en el discurso del entrevistado la información explícita y aquella que da cuenta de ciertas estructuras mentales, culturales e ideológicas (GRELE, 1991, p. 129). Asimismo, es importante enfatizar en el hecho de que el testimonio oral proporciona información sobre el significado que los informantes atribuyen al acontecimiento del que se habla (no sólo sobre el acontecimiento en sí mismo) (PORTELLI, 1991); en este sentido, el primer entrevistado (E.R., Buenos Aires 28-02-2007) comenzó su relato justificando su primer acercamiento a Tacuara con la admiración que sentía por la organización, su vistosa simbología y su patriotismo. A su vez, se preocupaba por recordar (a modo de excusa de muchas cosas que su militancia conllevaría) sus escasos catorce años de edad cuando se inició en el movimiento, con el cual seguiría, en realidad, vinculado casi diez años más. Es interesante aquí observar que, sin que de parte del entrevistador haya habido muestra de valoración alguna, el entrevistado se preocupaba por justificar su filiación a Tacuara de las maneras

Revista Eletrônica da ANPHLAC, n.11, p. 8-39, jul./dez. 2011. http://revista.anphlac.org.br/index.php/revista 
más diversas durante todo su relato. Así, por ejemplo, menciona a ex compañeros que hoy ocupan cargos públicos en el gobierno (al igual que el mismo), buscando con esto, posiblemente, borrar con un baño de legitimidad la vergüenza a la que se condenaba a los ex-militantes de Tacuara.

Del mismo modo, elementos centrales del imaginario del grupo encuentran justificativos, desde la perspectiva presente del entrevistado (que al momento de la entrevista era funcionario público). En este sentido, por ejemplo, excusa al antidemocratismo de Tacuara con el momento histórico del peronismo proscripto en el que se inscribió y el culto a la virilidad es explicado en base a la tradicional cultura machista argentina.

De la misma manera, con respecto al antisemitismo asegura que es entendible si se considera el contexto de la posguerra en el que Tacuara vivía: lo que Hitler había hecho (o mejor, "de lo que se lo acusaba") aún no era conocido por ellos. En general, dice, Tacuara admiraba de Hitler y del Eje su nacionalismo, la recuperación económica de sus países que supieron lograr, y hasta "hubo quienes se sentían cautivados por el fascismo europeo". Es que, explica, "hay cosas que hoy no se entenderían". También es desmentida la responsabilidad de Tacuara en el caso Sirota y la joven es recordada durante la entrevista con cierta ironía. Por otro lado, el entrevistado sugiere que estuvo exiliado en Méjico y con ello recuerda que fue un militante de izquierda en la década de los setenta y que se vio obligado a exiliarse en el exterior para sobrevivir, mientras muchos de sus compañeros cayeron víctimas del terrorismo de estado.

Asimismo, el entrevistado hizo referencia constantemente al libro de reciente publicación de Daniel Gutman sobre Tacuara. Esto dejaba entrever que las aseveraciones críticas de la investigación de Gutman (que según él partirían del falso preconcepto de que Tacuara era antisemita, lo que habría sesgado todo su análisis) sobrevolaban la situación de entrevista y funcionaban como una especie de interlocutor oculto detrás de las preguntas abiertas y generales que se le realizaban. Es decir que, no sólo la imagen que el entrevistado

Revista Eletrônica da ANPHLAC, n.11, p. 8-39, jul./dez. 2011. http://revista.anphlac.org.br/index.php/revista 
tenía de la entrevistadora, sino también aquella que el creía predominante en la opinión pública, principalmente a partir del libro de Gutman - y a la cual quería llegar a través de la entrevistadora - eran los factores principales que guiaban su relato.

En este marco discursivo y continuando con la línea exculpatoria de Bardini, el entrevistado se distancia de un grupo de "otros" cuya militancia se diferenciaría de la suya por nuclear todo aquello que hoy es visto como reprobable. Estos "otros" - los sectores más criticados por su antisemitismo e influencias fascistas - , por ejemplo, eran los que habían ido a cuidar la casa de la familia de Eichmann en 1960, luego de que se supiese que había sido capturado por el Mossad para ser enjuiciado en Israel como criminal de guerra.

El segundo entrevistado (Y.G., Buenos Aires, 18-04-2007), ex militante del MNT y amigo del primero, se mostraba mucho más relajado y dueño de la situación de entrevista. En términos generales, veía su paso por Tacuara casi como una travesura infantil, con anécdotas graciosas y nostálgicas y lejos de intentar justificar acciones cuestionables del grupo, desacreditaba su veracidad y les restaba importancia. Por ejemplo, ante la pregunta acerca de los rituales de iniciación que realizaban en la tumba del héroe mártir de Tacuara, Passaponti, asegura que es tan sólo un mito. "Si", afirma, "quizás hubieron algunos trasnochados que lo hacían... a alguien se le ocurrió el delirio de ir a jurar a la tumba.... de ahí se generó todo un delirio necrófilo...rituales nazis... Pero la verdad es que es una gansada total y absoluta". En este marco introduce la historia de Passaponti, el estudiante común (no el héroe), para explicar que, en realidad, sólo se trata de una mitología inventada. Del mismo modo atenúa, a través de una particular selección de vocabulario, otras acciones de Tacuara (por ejemplo utiliza la expresión "salíamos a hacer bochinche", para referirse a las acciones antisemitas de las que se los había acusado).

Por otra parte, con respecto a la violencia política destaca que Tacuara era, en realidad, un movimiento pacífico que fue obligado a cambiar su naturaleza, debido a que la sociedad no fue pacífica con ellos. Es decir, según este testimonio, el MNT siempre habría sido perseguido por su revisionismo, lo que se explicaría por el contexto del peronismo

Revista Eletrônica da ANPHLAC, n.11, p. 8-39, jul./dez. 2011. http://revista.anphlac.org.br/index.php/revista 
proscripto en el que se originó el movimiento. A este argumento agrega que "a esa edad tenés una inconsciencia total y absoluta". Sin embargo ante la pregunta de por qué se decía que eran nazis, admite que había ciertos sectores al interior de la agrupación que simpatizaban con esta ideología, pero solamente de una manera romántica. Al respecto sostiene que "hay algo que es muy romántico, y es la admiración por ese combate perdido. Algunos admiraban la resistencia de Berlín (ipelean entre los escombros.. con nada!). La república italiana también... combatían por el honor, con todo ya perdido... Eso es algo fascinante para los jóvenes". En este sentido la "fascinación por la lucha por el honor" va emergiendo en el relato como el patrón clave. Es decir, en un comienzo este entrevistado no parece preocuparse por justificar su militancia en Tacuara. Sin embargo, de modo paulatino va surgiendo esa justificación implícita que determina su coherencia de yo, su reconciliación con su propio pasado a partir de su presente. Desde su punto de vista, el heroísmo y la lucha son resignificados, guardando una distancia prudente con respecto a la historia política de aquellos movimientos citados por el mismo. Es, más bien, la literatura de aventuras la que otorga, para el entrevistado, el marco interpretativo a estas "luchas heroicas". Esto se debe, según él mismo hace explícito, a la influencia de las novelas de Emilio Salgari, que los jóvenes Tacuara leían obsesivamente durante su infancia. Había como recuerda el entrevistado - todo un sentido de la existencia muy particular, basado en esta heroicidad romántica representada tanto por los partisanos, los fascistas italianos del último tiempo, los republicanos españoles y los caballeros medievales, presentes en la cotidianidad del grupo a través de la Cruz de Malta. "Se trata de la admiración por el que pelea por el ideal sin importarle si va a ganar o perder. Para nosotros el combate es un fin en sí mismo, si está coronado por la victoria mejor pero si no, hay que pelear igual", agrega. Así, se esfuerza en recuperar una imagen de Tacuara como un grupo que de la nada se esforzaba por luchar por sus ideales, aunque, vistos desde el hoy, resulten un poco infantiles, reconoce.

Estas representaciones y valoraciones que salen a la luz en los relatos de quienes

Revista Eletrônica da ANPHLAC, n.11, p. 8-39, jul./dez. 2011.

http://revista.anphlac.org.br/index.php/revista 
fueron militantes de Tacuara se encuentran en permanente diálogo con los discursos periodísticos, bibliográficos y audiovisuales analizados en el apartado anterior. En este sentido, el lente de la memoria, a través del cual los ex tacuaristas acceden a su pasado los obliga a hacer pie en el presente y es ahí donde no pueden ignorar los discursos hegemónicos sobre su propia militancia. De este modo, se preocupan durante su relato, ya sea por distanciarse de una Tacuara nazi y exclusivamente ultra derechista, o por justificar su paso por el grupo con la excusa del romanticismo e idealismo propios de la juventud.

\section{Conclusiones}

A lo largo del presente trabajo se analizaron los cambios producidos en los discursos sociales sobre Tacuara en los últimos años, según se deduce del análisis de narrativas contemporáneas emblemáticas sobre el tema. Estas transformaciones se sucedieron en dos etapas. En primer lugar, Tacuara se consideró una agrupación nazi y de ultra-derecha que nucleó a adolescentes nacionalistas, quienes más tarde ocuparían roles centrales de los gobiernos de Carlos Saúl Menem.

Desde fines del 2002 hasta el 2008, principalmente las publicaciones de diversos libros y la realización de materiales audiovisuales sobre Tacuara dan cuenta de un viraje en las configuraciones de sentido con respecto a este grupo. Éste depende de su relación con la militancia de izquierda durante los años setenta (cuya memoria fue recuperada desde el discurso oficial) y, a partir de dicho vínculo se comienza a percibir al momento de militancia tacuarista como una etapa de paso hacia el sacrificio (materializado en la desaparición, muerte o exilio) de la década siguiente.

Así, Tacuara comienza a ser considerada por la memoria hegemónica como un momento de preparación para la militancia progresista futura. Esto también se extiende a

Revista Eletrônica da ANPHLAC, n.11, p. 8-39, jul./dez. 2011. http://revista.anphlac.org.br/index.php/revista 
otros casos que no necesariamente encajan en este modelo pero que se valen de algunos de sus elementos, como por ejemplo el idealismo. No obstante ello, junto a estas representaciones aun coexisten otras como, por ejemplo, aquellas que ven en Tacuara el germen que habría de engendrar a una guerrilla armada en los setenta aún demonizada. En este contexto, los testimonios de los ex tacuaristas establecen una relación dialógica con los discursos sociales hegemónicos que los afectan inevitablemente al momento de recordar y transmitir su propio pasado.

Para concluir, es importante destacar que de este análisis resulta innegable la influencia de los cambios en los regímenes de memoria. Los vaivenes de las formas de rememorar el pasado reciente configuran los diversos discursos sociales actuales acerca de Tacuara. Por este motivo, el análisis de las representaciones actuales sobre este grupo sólo pueden entenderse a partir de los parámetros establecidos por los regímenes de memoria que las rigen.

\section{Referencias bibliográficas}

BARDINI, Roberto. Tacuara. La pólvora y la sangre. México D.F.: Editorial Océano, 2002.

BERAZA, Luis Fernando. Nacionalistas. La trayectoria de un grupo polémico (19271983). Buenos Aires: Editorial Puerto de Palos, 2005.

BUCHRUCKER, Cristián. Nacionalismo y Peronismo. La Argentina en la crisis ideológica mundial (1927-1955). Buenos Aires: Sudamericana, 1999.

CRENZEL, Emilio. La historia política del Nunca Más. La memoria de las desapariciones en la Argentina. Avellaneda: Siglo XXI, 2008.

DANDAN, Alejandra; HEGUY, Silvina. Joe Baxter. Del nazismo a la extrema izquierda. La historia secreta de un guerrillero. Buenos Aires: Grupo Editorial Norma, 2006.

DEVOTO, Fernando. Nacionalismo, fascismo y tradicionalismo en la Argentina moderna. Buenos Aires: Siglo XXI, 2002.

Revista Eletrônica da ANPHLAC, n.11, p. 8-39, jul./dez. 2011.

http://revista.anphlac.org.br/index.php/revista 
FERRO, Marc. Historia contemporánea y cine. Madrid: Ariel, 2000.

FINCHELSTEIN, Federico. Fascismo, liturgia e imaginario: el mito del General Uriburu y la Argentina nacionalista. Buenos Aires: FCE, 2002.

GALVÁN, María Valeria. El Movimiento Nacionalista Tacuara y sus agrupaciones derivadas: una aproximación desde la historia cultural. 2008. Tesis (Maestría en Sociología de la Cultura) - IDAES, Universidad Nacional de San Martin, Buenos Aires, 2008.

GASPARINI, Juan. Manuscrito de un desaparecido en la ESMA. El libro de Jorge Caffatti. Buenos Aires: Grupo Editorial Norma, 2006.

GLÜCK, Mario. Tradición xenófoba y violencia política: Tacuara en Santa Fe a principios de la década del 60. In: JORNADAS HISTORIA, ETNICIDAD Y LITERATURA LATINOAMERICANA. 2000, Mendoza. La experiencia del judaísmo contemporáneo. Mendoza: Fundación Auge y Universidad Hebrea de Jerusalén, 2000.

GRELE, Ronald J. Movimiento sin meta: Problemas metodológicos y teóricos en la historia oral. In: SCHWARZSTEIN, Dora (Ed.). La Historia Oral. Buenos Aires: Centro Editor de América Latina, 1991.

GUTMAN, Daniel. Tacuara. Historia de la primera guerrilla urbana argentina. Buenos Aires: Ediciones B, 2003.

JAMES, Daniel. Doña María. Historia de vida, memoria e identidad política. Buenos Aires: Manantial, 2004.

JELIN, Elizabeth. La conflictiva y nunca acabada mirada sobre el pasado. In: LEVIN, Florencia; FRANCO, Marina (Eds.) Historia reciente. Perspectiva y desafíos para un campo en construcción. Buenos Aires: Paidós, 2007.

KRACAUER, Siegfried. Teoría del cine. La redención de la realidad física. Buenos Aires: Paidós, 2002.

LARRAQUY, Marcelo; CABALlERO, Roberto. Galimberti. Buenos Aires: Grupo Editorial Norma, 2000.

LVOVICH, Daniel; BISQUERT, Jacquelina. La cambiante memoria de la dictadura militar desde 1984: Discursos públicos, movimientos sociales y legitimidad democrática. Buenos Aires: UNGS - Biblioteca Nacional, 2008.

NAVARRO GERASSI, Marysa. Los Nacionalistas. Buenos Aires: Editorial Jorge Álvarez, 1968.

NICHOLS, Bill. La representación de la realidad. Cuestiones y conceptos sobre el

Revista Eletrônica da ANPHLAC, n.11, p. 8-39, jul./dez. 2011.

http://revista.anphlac.org.br/index.php/revista 
documental. Barcelona: Paidós, 1997.

ORLANDINI, Juan Esteban. Tacuara...hasta que la muerte nos separe de la lucha. Historia del Movimiento Nacionalista Tacuara 1957-1972. Buenos Aires: Centro Editor Argentino, 2008.

PORTELLI, Alessandro Lo que hace diferente a la historia oral. In: SCHWARZSTEIN, Dora (Ed.). La Historia Oral. Buenos Aires: Centro Editor de América Latina, 1991. .

ROSENSTONE, Robert. El pasado en imágenes. El desafío del cine a nuestra idea de historia. Barcelona: Ariel, 1997.

SEMÁN, Pablo. Bajo continuo. Exploraciones descentradas sobre cultura popular y masiva. Buenos Aires: Editorial Gorla, 2006.

SENKMAN, Leonardo. El antisemitismo bajo dos experiencias democráticas: Argentina 1959/1966 y 1973/1976. In: SENKMAN, Leonardo (Ed.). El antisemitismo en la Argentina. Buenos Aires: CEAL, 1989.

Revista Eletrônica da ANPHLAC, n.11, p. 8-39, jul./dez. 2011.

http://revista.anphlac.org.br/index.php/revista 